\title{
In Vitro Digestion of Tire Particles in a Fish Model (Oncorhynchus mykiss): Solubilization Kinetics of Heavy Metals and Effects of Food Coingestion
}

Thibault Masset,* Benoit J. D. Ferrari, Dean Oldham, William Dudefoi, Matteo Minghetti, Kristin Schirmer, Alan Bergmann, Etienne Vermeirssen, and Florian Breider

Cite This: Environ. Sci. Technol. 2021, 55, 15788-15796

Read Online

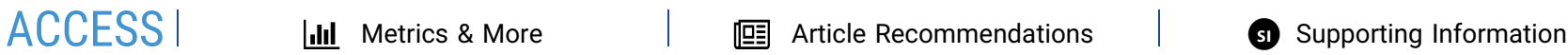

ABSTRACT: Tire and road wear particles (TRWP) have been shown to represent a large part of anthropogenic particles released into the environment. Nevertheless, the potential ecological risk of TRWP in the different environmental compartments and their potential toxic impacts on terrestrial and aquatic organisms remain largely underinvestigated. Several heavy metals compose TRWP, including $\mathrm{Zn}$, which is used as a catalyst during the vulcanization process of rubber. This study investigated the solubilization potential of metals from cryogenically milled tire tread (CMTT) and TRWP in simulated gastric fluids $\left(\mathrm{SF}_{\mathrm{GASTRIC}}\right)$ and simulated intestinal fluids ( $\mathrm{SF}_{\text {INTESTINAL }}$ ) designed to mimic rainbow trout (Oncorhynchus mykiss) gastrointestinal conditions. Our results indicate that the solubilization of heavy metals was greatly enhanced by gastrointestinal fluids compared to that by mineral water. After a $26 \mathrm{~h}$ in
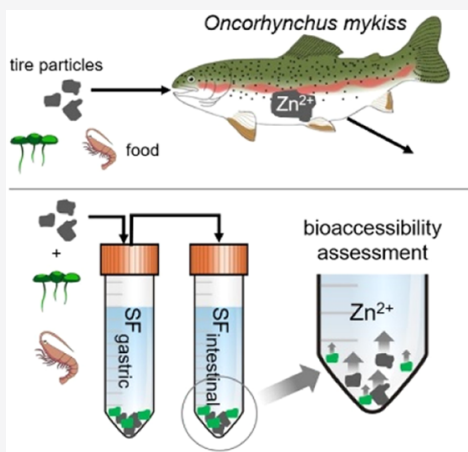

bioaccessibility

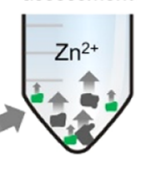

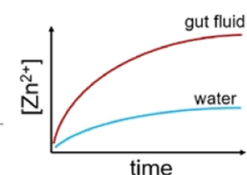

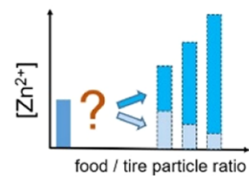

vitro digestion, 9.6 and $23.0 \%$ of total $\mathrm{Zn}$ content of CMTT and TRWP,

respectively, were solubilized into the simulated gastrointestinal fluids. Coingestion of tire particles (performed with CMTT only) and surrogate prey items (Gammarus pulex) demonstrated that the animal organic matter reduced the amount of bioavailable $\mathrm{Zn}$ solubilized from CMTT. Contrastingly, in the coingestion scenario with vegetal organic matter (Lemna minor), high quantities of $\mathrm{Zn}$ were solubilized from L. minor and cumulated with $\mathrm{Zn}$ solubilized from CMTT.

KEYWORDS: tire, tyre, TRWP, heavy metals, microplastics

\section{INTRODUCTION}

The occurrence and fate in the environmental compartments and the potential threat for aquatic organisms of microplastic particles $(<5 \mathrm{~mm})$ have recently gained interest as plastic production has continued increasing throughout the past decades (359 million tons produced in $2018^{1}$ ). Whether tire and road wear particles (TRWP) should be considered as microplastics is a point of discussion due to its composition being mainly elastomeric (polymers irreversibly hardened during the curing process), in contrast with thermoplastics (polymers undergoing deformation with temperature variations). However, TRWP are nowadays included in global and regional estimations of microplastics emissions into the environment. Similarly to microplastics, global TRWP emissions are constantly increasing and were recently estimated to reach $2.89 \times 10^{6}$ tons/year in $2019 .^{2}$ In Switzerland, TRWP were estimated to represent up to $61 \%$ of microplastics entering Lake Geneva. ${ }^{3}$

TRWP are generated by the friction of tires onto the road pavement (RP) while driving. Thus, its composition consists of a rubbery polymeric backbone with inclusions of road minerals and bitumen. ${ }^{4}$ Several additives are used during the manufacture of tires in the rubber vulcanization process. Zinc oxide is commonly used as a sulfur vulcanization catalyst and represents up to 2.5 mass \% of the final tire composition. ${ }^{5}$ Friction is an important factor that is responsible for the generation of TRWP and causes parts of the bituminous binder and minerals from the RP to be embedded in the tire matrix. Therefore, it was shown that metals originating from the pavement are incorporated into TRWP. ${ }^{4}$ Moreover, brake particles generated during braking have been shown to deposit on the road. ${ }^{6,7}$ These particles, which are composed of high amounts of $\mathrm{Cu}, \mathrm{Fe}, \mathrm{Sb}, \mathrm{Pb}$, and $\mathrm{Ba},{ }^{6,8}$ are also susceptible to be incorporated into TRWP.

Received: July 1, 2021

Revised: October 4, 2021

Accepted: November 10, 2021

Published: November 22, 2021 
Most TRWP are emitted as nonairborne particles (9099.9\% $)^{9}$ due to their size $(4-120 \mu \mathrm{m})^{4}$ and density $(1-2 \mathrm{~g}$ $\left.\mathrm{cm}^{-1}\right) .{ }^{10}$ Indeed, high concentrations of TRWP (100-100,000 $\mathrm{mg} \mathrm{kg}^{-1}$ ) have been reported on roadside soil and in sediments (1000 $\mathrm{mg} \mathrm{kg}^{-1}$ ) after transport by runoff water. ${ }^{10}$ Therefore, involuntary ingestion of these particles by terrestrial and aquatic organisms may occur in the environment. The characterization of microplastics (polymer type, size, sources, and global distribution) ingested in situ by aquatic organisms is getting more attention, and quantitative data (number of particles/organisms or gut) are becoming available. ${ }^{11,12}$ However, although tire particles have also recently been detected in fish gut, ${ }^{11}$ the quantity of tire particles susceptible to be in contact with the gastrointestinal fluids of fish remains unknown.

The toxicity of TRWP on organisms remains uncertain after both acute and long-term exposure. Several studies demonstrated the toxic effects on aquatic and terrestrial organisms, whereas others showed no effects of the particles or its leachates. ${ }^{13-15}$ The toxicity of TRWP on fish has been scarcely investigated $^{16,17}$ despite the fact that ingestion of TRWP by several fish estuarine species has been demonstrated. ${ }^{11}$ Determining the gastrointestinal bioaccessibility of particlebound chemicals is the first critical step into the risk assessment process of TRWP-associated chemicals. The solubilization of $\mathrm{Cd}$ into natural and simulated gastrointestinal fluids of invertebrates from various types of microplastics has been reported, ${ }^{18}$ demonstrating the solubilization potential of polymer-bound elements during gut transit. In vitro digestions of tire particle/sediment mixtures have been performed to investigate the solubilization of $\mathrm{Zn}$ into the simulated gastrointestinal fluid of benthic invertebrates. ${ }^{19} \mathrm{Zn}$ was shown to be highly solubilized into the gastrointestinal fluids compared to water. Taken together, the information regarding the bioaccessibility of TRWP-associated metals remains sparse. ${ }^{13}$ Therefore, this study aims to further elucidate the role of tire particle ingestion for metal bioaccessibility via (i) investigating the solubilization kinetics of metals from cryogenically milled tire tread (CMTT) and lab-generated TRWP into simulated gastric and intestinal fluids of a fish model species: the rainbow trout (Oncorhynchus mykiss) and (ii) assessing the impact of influencing factors, such as coingestion of natural food organic matter, on bioaccessible $\mathrm{Zn}$ (defined as soluble $\mathrm{Zn}$ available for uptake by epithelial cells in the gut).

\section{MATERIALS AND METHODS}

Materials. Two different materials were used in this study. The tread of tires (cryogenically milled tire tread $=$ CMTT), commonly used in exposure and toxicological studies related to tires, was produced along with lab-generated TRWP as a surrogate for environmental TRWP. As only a low amount of lab-generated TRWP could be obtained due to production limitations, most of the experiments were performed with CMTT, as explicitly stated hereafter. The generation of CMTT and TRWP has been described thoroughly in a previous study. ${ }^{20}$ Briefly, to generate CMTT, only the upper layer of the tire treads from Pirelli (Sottozero 3), Michelin (Primacy 3), and Bridgestone (Saetta Touring 2) (ratio 1:1:2, respectively), excluding any other component of the tire (sub-tread and belt wedge), were removed using an applicable cutting tool and cut into small pieces of $1 \mathrm{~cm}^{3}$ using industrial scissors and a water jet machine. The tire pieces were then cryogenically milled using a hammer mill (model A, Pulva) to generate CMTT. The TRWP were produced on a road simulator at the Karlsruhe Institute of Technology (KIT). The road simulator consisted of a drum that was coated with RP, composed of a mixture of minerals and bituminous binder, representing the typical pavement from European roads. A tire was put in contact with the drum, and stone dust was added to the drum to increase the friction. Pressure was applied to the tire, and the rotation of the drum generated TRWP, which were collected using a vacuum system in accordance with ISO TS $22638 .^{21}$ This process was applied to the three types of tires used to generate CMTT (see above), and a composite sample with the same tire ratio as that for CMTT was prepared. A bulk sample $(1 \mathrm{~g})$ of the RP used for the generation of the TRWP containing minerals and parts of the bituminous binder was also collected from the road simulator. All particles were collected and stored in amber glass vials in dark at room temperature. More details regarding the CMTT and TRWP physical/chemical characteristics (size distribution, polymer content, and electronic microscopy images) are presented in Tables S1 and S2 and Figures S1 and S2.

The composition of simulated gastric fluid $\left(\mathrm{SF}_{\mathrm{GASTRIC}}\right)$ and simulated intestinal fluid $\left(\mathrm{SF}_{\text {INTESTINAL }}\right)$ is presented in Table S3. Briefly, both $\mathrm{SF}_{\text {GASTRIC }}$ and $\mathrm{SF}_{\text {INTESTINAL }}$ consisted of a luminal buffer adapted from Leibovitz's L15 cell culture medium to mimic the composition of the lumen of the fish intestine. $^{22}$ The fluids were designed to be used in combination with a cell line isolated from the trout intestine, RTgutGC, which is cultured using L-15 medium. ${ }^{23}$ Purified pepsin (Sigma-Aldrich) was added to the luminal buffer at a concentration of $12.5 \mathrm{U} \mathrm{mg}^{-1}$ of protein, and $\mathrm{pH}$ was adjusted

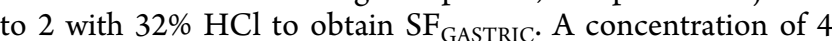
$\mathrm{mg} \mathrm{mL}^{-1}$ of the porcine bile extract (Sigma-Aldrich) and $2 \mathrm{mg}$ $\mathrm{mL}^{-1}$ pancreatin (Sigma-Aldrich) were added to the luminal

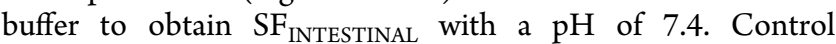
experiments were performed in mineral water (MW) (Evian) to compare the solubilization of metals with simulated gastrointestinal fluids. The composition of Evian water is provided in Table S4. The surface tension of SF INTESTINAL was measured with a goniometer (EasyDrop, Kruss), and the presence, size, and stability of micelles were assessed by dynamic light scattering (Zetasizer ZS).

Determination of Elemental Composition of Tire Particles. To quantify the metal content of CMTT, TRWP, and RP, acid-digestion of the particles was performed. The following method ensured the complete mineralization of the samples as no sample remnants were collected during the postdigestion filtration step. Triplicates of $250 \mathrm{mg}$ of each material were placed into Teflon vessels, and $9 \mathrm{~mL}$ of $69 \%$ $\mathrm{HNO}_{3}$ and $1 \mathrm{~mL}$ of Milli-Q water were added. The vessels were placed into a microwave reactor (multiwave Pro Anton Paar) and heated at $200{ }^{\circ} \mathrm{C}$ with the following conditions: 15 min heating up to $200{ }^{\circ} \mathrm{C}, 45 \mathrm{~min}$ steady conditions at $200{ }^{\circ} \mathrm{C}$ and $20 \mathrm{bar}$, and $10 \mathrm{~min}$ cooling to $70{ }^{\circ} \mathrm{C}$. Then, the digesta were filtered through $0.45 \mu \mathrm{m}$ filters (Chromafil), diluted 50fold, and analyzed for metals as described below.

Determination of the Morphology and Particle Size Analysis. A qualitative analysis of the particle morphology was performed on CMTT and TRWP before and after the in vitro digestion using scanning electron microscopy (GeminiSEM 300, Zeiss). This was done in order to assess the general morphology of the particles and to investigate any morphological changes at the surface of the particles that might be 
resulting from the exposure to the simulated gastrointestinal fluids. Particle size distributions of CMTT and TRWP were evaluated using laser diffraction, and the main composition of TRWP was evaluated by thermogravimetric analysis (Tables S1 and S2).

Experimental Design. The following experiments were designed to investigate the solubilization of metals originating from CMTT and TRWP into the simulated gastrointestinal fluids of rainbow trout. The solubilization kinetics of several metals, the impact of the CMTT concentration on $\mathrm{Zn}$ solubilization, and the impact of the coingestion of food on Zn bioaccessibility were explored.

In Vitro Digestions. Solubilization Kinetics of Metals from CMTT and TRWP. Overall, the in vitro digestion consisted of $3 \mathrm{~h}$ digestion in $\mathrm{SF}_{\mathrm{GASTRIC}}$ to mimic the transit time in the fish stomach, followed by $23 \mathrm{~h}$ digestion in SF INTESTINAL $_{\text {, }}$ estimated as the average transit time in the fish small intestine. ${ }^{24} \mathrm{~A}$ total of $1.5 \mathrm{~g}$ of either CMTT or TRWP was added to $250 \mathrm{~mL}$ polypropylene flasks, and $150 \mathrm{~mL}$ of $\mathrm{SF}_{\text {GASTRIC }}$ was incorporated at $t=0$ in order to obtain a solid/ liquid ratio of 0.01 . The flasks were immediately placed on an orbital shaker at $130 \mathrm{rpm}$ in dark at room temperature (20 $\left.{ }^{\circ} \mathrm{C}\right)$. Aliquots of $4 \mathrm{~mL}$ of the mixture were regularly collected by pipetting, immediately filtered at $0.45 \mu \mathrm{m}$ (Chromafil), and stored in polypropylene tubes at $4{ }^{\circ} \mathrm{C}$ before analysis. After the $3 \mathrm{~h}$ in vitro digestion in $\mathrm{SF}_{\mathrm{GASTRIC}}$, the remaining $\mathrm{SF}_{\text {GASTRIC }}$ was removed by centrifugation and replaced by the appropriate amount of SF INTESTINAL to maintain a solid/liquid ratio of 0.01 . The same process (pipetting at regular intervals and filtration) was repeated until a digestion time of $23 \mathrm{~h}$. The control experiment consisted of using $\mathrm{MW}$ instead of $\mathrm{SF}_{\mathrm{GASTRIC}}$ and

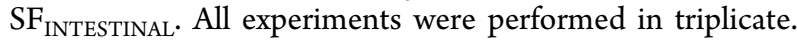

Impact of the CMTT Concentration on Zn Solubilization. The relationship between the quantity of tire particles used in in vitro digestions and the quantity of metals solubilized was evaluated only with CMTT due to the limited quantity of TRWP available. The same protocol as that for the solubilization kinetics experiments was used with the exception that the digestions in $\mathrm{SF}_{\text {GASTRIC }}$ and $\mathrm{SF}_{\text {INTESTINAL }}$ were tested separately and not with a sequential approach in order to investigate the different solubilization patterns of $\mathrm{Zn}$ in both fluids. Three CMTT concentrations (0.1, 0.01, and $0.001 \mathrm{~g}$ $\mathrm{mL}^{-1}$ ) were used for a total digestion time with $\mathrm{SF}_{\text {GASTRIC }}$ of 3 h. The same experiment was repeated with $S_{\text {INTESTINAL }}$ for 24 h. All experiments were performed in triplicate and conducted along with a MW control instead of $\mathrm{SF}_{\text {GASTRIC }}$ or SF $\mathrm{SF}_{\text {INTESTINAL }}$.

Food Organic Matter Coingestion Scenarios. To investigate the effect of the coingestion of food organic matter on the bioaccessible fraction of $\mathrm{Zn}$, in vitro digestions with CMTT only and with the addition of either Gammarus pulex (JBL) or Lemna minor obtained from a culture in a fish store were performed. These species were chosen as surrogates for animal and vegetal food items. Briefly, whole freeze-dried G. pulex and L. minor were ground into powder with a mortar and pestle and were incorporated into an $\mathrm{SF}_{\mathrm{GASTRIC}}$ solution with CMTT $(75 \mathrm{mg})(\mathrm{CMTT} /$ liquid ratio $=0.01$ and 0.0033 for G. pulex and L. minor, respectively). The flasks were immediately placed on an orbital shaker at $130 \mathrm{rpm}$ in dark at room temperature $\left(20^{\circ} \mathrm{C}\right.$ ) for $3 \mathrm{~h}$. The mixtures were then passed through 0.45 $\mu \mathrm{m}$ filters (Chromafil) and stored in polypropylene tubes at 4 ${ }^{\circ} \mathrm{C}$ until analysis. The same protocol was repeated with $\mathrm{SF}_{\text {INTESTINAL }}$ instead of $\mathrm{SF}_{\text {GASTRIC }}$ for digestion for $23 \mathrm{~h}$. Three food/CMTT ratios of 2:1, 5:1, and 10:1 with the CMTT concentration of $0.01 \mathrm{~g} \mathrm{~mL}^{-1}$ held constant were tested. Although higher ratios are likely to occur in the environment, the introduction of high amounts of food in our in vitro digestion vessels led to a very viscous solution, preventing the processing of the samples. Therefore, scenarios considering a food/CMTT ratio $>10$ could not be tested. A negative control containing no addition of food organic matter and only CMTT was performed. Control experiments with food organic matter only (without CMTT) whose quantities corresponded to the different ratios of 2:1, 5:1, and 10:1 were also performed. All experiments were performed in triplicate.

Metal Analyses. Analyses of $\mathrm{Zn}$ were performed on an inductively coupled plasma (ICP) optical emission spectrometer (Shimadzu ICPE-9000) for microwave digested extracts since $\mathrm{Zn}$ was present in high amounts in CMTT and TRWP. Analyses of Ti, V, Cr, Mn, Fe, Co, Ni, Cu, Zn, Mo, Ba, and Pb, present in low quantities in particles and in simulated fluids, were performed on a triple quadrupole ICP mass spectrometer (Agilent 8900). For both instruments, calibration curves were established with 10 points of appropriate concentration from a multi-element standard solution (Inorganic Ventures). Quality control solutions were processed between a series of 10 samples. More information regarding the instrument settings and QA/QC are available in Text S1.

\section{RESULTS AND DISCUSSION}

Metal Content of the Particles. Elemental analysis of CMTT revealed high quantities of $\mathrm{Zn}\left(7780 \pm 69 \mu \mathrm{g} \mathrm{g}^{-1}\right)$, as expected from its use in the vulcanization process of rubber (Table 1). All other metals were detected in quantities of $<20$

Table 1. Metal Concentration $\left(\mu \mathrm{g} \mathrm{g}^{-1}\right)$ in CMTT, TRWP, and RP Particles ${ }^{a}$

$\begin{array}{cccccc}\text { metal } & \begin{array}{c}\text { CMTT } \\ (n=3)\end{array} & (\mathrm{sd}) & \begin{array}{c}\text { TRWP } \\ (n=3)\end{array} & \begin{array}{c}\text { (sd) } \\ \mathrm{RP}(n=1)\end{array} \\ \mathrm{Zn} & 7780 & (69) & 1448 & (76) & <250 \\ \mathrm{Li} & 5.2 & (0.2) & 8.1 & (0.3) & 2.0 \\ \mathrm{Ti} & 16.7 & (4.6) & 141.2 & (5.5) & 141.2 \\ \mathrm{~V} & 1.2 & (0.0) & 14.5 & (0.4) & 7.1 \\ \mathrm{Cr} & 4.9 & (0.5) & 229 & (36.5) & 30.8 \\ \mathrm{Mn} & 1.3 & (0.1) & 156 & (9.1) & 39.4 \\ \mathrm{Fe} & 82.9 & (3.7) & 4863 & (43) & 1219 \\ \mathrm{Co} & 7.5 & (0.1) & 26.4 & (2.2) & 0.7 \\ \mathrm{Ni} & 3.3 & (0.2) & 26.0 & (2.4) & 2.8 \\ \mathrm{Cu} & 2.3 & (0.0) & 53.3 & (20.9) & 2.5 \\ \mathrm{Ba} & 8.3 & (0.7) & 88.3 & (6.4) & 13.6 \\ \mathrm{~Pb} & 3.8 & (0.0) & 31.2 & (2.4) & 4.7\end{array}$

$a_{\mathrm{sd}}=$ standard deviation and $n=$ number of replicates.

$\mu \mathrm{g} \mathrm{g}^{-1}$ with the exception of $\mathrm{Fe}\left(83 \pm 4 \mu \mathrm{g} \mathrm{g}^{-1}\right)$. Concentrations of metals measured in CMTT were consistent with the concentrations reported for tire granulates ${ }^{5,25}$ and for tire tread. ${ }^{4}$

In contrast to CMTT, TRWP contained higher quantities of Fe $\left(4863 \pm 432 \mu \mathrm{g} \mathrm{g}^{-1}\right)$ and $\mathrm{Ti}, \mathrm{Cr}, \mathrm{Mn}, \mathrm{Co}, \mathrm{Ni}, \mathrm{Cu}, \mathrm{Ba}$, and $\mathrm{Pb}\left(20-300 \mu \mathrm{g} \mathrm{g}^{-1}\right)$. Lower concentrations of $\mathrm{Zn}(1448 \pm 76$ $\left.\mu \mathrm{g} \mathrm{g}^{-1}\right)$ were measured in TRWP than that in CMTT. This was related to the very low concentration of $\mathrm{Zn}$ detected in the $\mathrm{RP}\left(<250 \mu \mathrm{g} \mathrm{g}^{-1}\right)$ (Table 1). When incorporated into the polymer matrix of the tire, the RP likely acted as a dilution material and lowered the overall $\mathrm{Zn}$ concentration in TRWP. Kreider et al. $(2010)^{4}$ also observed a dilution effect of the road 


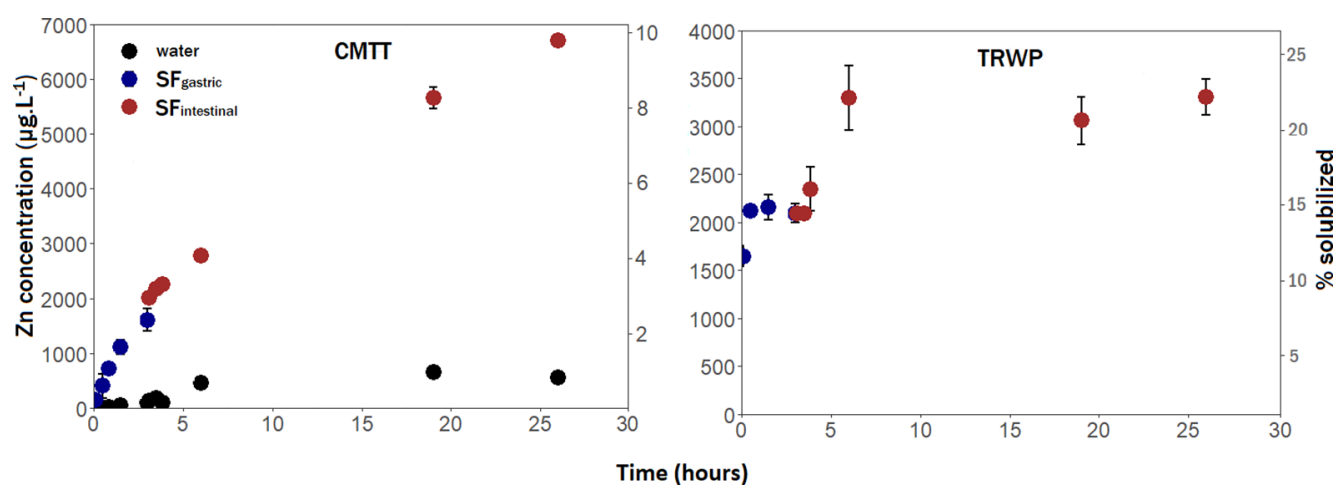

Figure 1. Solubilization kinetics of $\mathrm{Zn}$ in $\mathrm{SF}_{\mathrm{GASTRIC}}$ and $\mathrm{SF}_{\mathrm{INTESTINAL}}$, represented by the concentration of $\mathrm{Zn}$ solubilized in the fluid (left axis) and

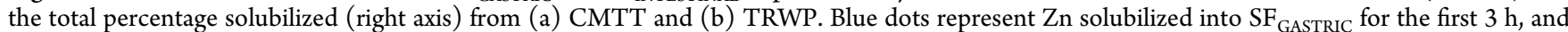
red dots represent $\mathrm{Zn}$ dissolved into $\mathrm{SF}_{\mathrm{INTESTINAL}}$ for the following $23 \mathrm{~h}$ of the in vitro digestion. Black dots represent $\mathrm{Zn}$ solubilized into $\mathrm{MW}$ (control) and are not displayed in (b) because values were less than the limit of quantitation. Error bars represent the standard deviation of the replicates $(n=3)$.

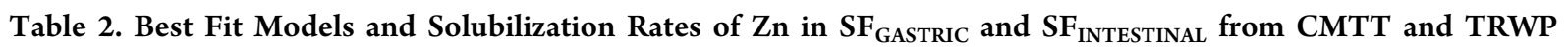

\begin{tabular}{|c|c|c|c|c|c|c|c|c|c|c|}
\hline & \multicolumn{5}{|c|}{$\mathrm{SF}_{\text {GASTRIC }}$} & \multicolumn{5}{|c|}{ SF $_{\text {INTESTINAL }}$} \\
\hline & model & $k$ & $95 \% \mathrm{CI}$ & $r_{\text {adj }}^{2}$ & $p$-value & model & $k$ & $95 \% \mathrm{CI}$ & $r_{\mathrm{adj}}^{2}$ & $p$-value \\
\hline CMTT & $\begin{array}{l}\text { diffusion-controlled } \\
\left(\mu \mathrm{g} \mathrm{L}^{-1} \mathrm{~min}^{-1 / 2}\right)\end{array}$ & 125.4 & $107.6-143.3$ & 0.93 & $<10^{-10}$ & $\begin{array}{l}\text { diffusion-controlled } \\
\left(\mu \mathrm{g} \mathrm{L}^{-1} \mathrm{~min}^{-1 / 2}\right)\end{array}$ & 139.2 & $130.4-148.0$ & 0.98 & $<10^{-16}$ \\
\hline TRWP & $\begin{array}{c}\text { diffusion-controlled } \\
\left(\mu \mathrm{g} \mathrm{L}^{-1} \mathrm{~min}^{-1 / 2}\right)\end{array}$ & 384.2 & $264.2-504.1$ & 0.87 & $<10^{-3}$ & $\begin{array}{l}\text { zeroth order } \\
\quad\left(\mu \mathrm{g} \mathrm{L}^{-1} \min ^{-1}\right)\end{array}$ & 6.6 & $4.5-8.8$ & 0.89 & $<10^{-4}$ \\
\hline
\end{tabular}

particles on the Zn concentration of lab-generated TRWP. As demonstrated here, the dilution effect observed by Kreider et al. (2010) correlated with the low concentration of $\mathrm{Zn}(48-86$ $\left.\mu \mathrm{g} \mathrm{g}^{-1}\right)$ reported in European RP. ${ }^{26}$

Higher concentrations of $\mathrm{Ti}, \mathrm{V}, \mathrm{Cr}, \mathrm{Mn}, \mathrm{Co}, \mathrm{Ni}, \mathrm{Cu}, \mathrm{Ba}$, and $\mathrm{Pb}$ were measured in TRWP than that in CMTT (Table 1). An explanation could be that the contamination of the drum used for the generation of the TRWP was partly responsible for the high values measured for these metals. Hence, the concentrations of $\mathrm{Ti}, \mathrm{Cr}, \mathrm{Mn}, \mathrm{Co}, \mathrm{Ni}, \mathrm{Ba}$, and $\mathrm{Pb}$ in TRWP from this study might be overestimated compared to that for the TRWP found in the environment. However, Legret et al. (2005) ${ }^{26}$ reported similar concentrations of $\mathrm{Fe}, \mathrm{Cr}, \mathrm{Cu}, \mathrm{Ni}$, and $\mathrm{Pb}$ in European pavement compared to that for the RP used in this study. Similarly to our study, an enrichment of $\mathrm{Fe}, \mathrm{Cr}, \mathrm{Co}, \mathrm{Cu}$, $\mathrm{Ni}$, and $\mathrm{Pb}$ in TRWP compared to that in tire tread was also demonstrated by Kreider et al. (2010). ${ }^{4}$ Recently, road dust collected in a highway tunnel was shown to contain comparable concentrations of $\mathrm{Ba}, \mathrm{Co}, \mathrm{Cr}, \mathrm{Pb}$, and $\mathrm{Zn}$ compared to that of the lab-generated TRWP used in our study. ${ }^{27}$ These results strengthen the hypothesis that TRWP can incorporate elements from the RP containing high concentrations of metals, resulting in an increase of the metal burden of these particles.

In Vitro Digestion of CMTT and TRWP. $\mathrm{Zn}$ was solubilized in $\mathrm{SF}_{\mathrm{GASTRIC}}$ and $\mathrm{SF}_{\mathrm{INTESTINAL}}$ both from the CMTT and the TRWP, which resulted in high concentrations in the gastrointestinal fluid after the in vitro digestion (Figure 1). Four kinetic models (zeroth-, first-, and second-order kinetics and the diffusion-controlled model ${ }^{19,28}$ ) were applied to fit our data in order to investigate the mechanisms driving Zn solubilization (Table S5). The solubilization kinetics of $\mathrm{Zn}$ from CMTT into $\mathrm{SF}_{\text {GASTRIC }}$ and $\mathrm{SF}_{\text {INTESTINAL }}$ was best represented with the diffusion-controlled model (Table 2). As the mixing was ensured during the time course of the experiment, this suggests that the solubilization was limited by intraparticle diffusion, leading to a concentration gradient at the surface of the particles.

For CMTT, after the $3 \mathrm{~h}$ digestion in $\mathrm{SF}_{\mathrm{GASTRIC}}, 2.1 \%$ of the total $\mathrm{Zn}$ was solubilized, and at the end of the digestion $(3 \mathrm{~h}$ in $\mathrm{SF}_{\mathrm{GASTRIC}}$ only followed by $23 \mathrm{~h}$ in $\mathrm{SF}_{\text {INTESTINAL }}$ only), $9.6 \%$ of the total $\mathrm{Zn}$ was solubilized, which represented a final concentration of $6.7 \mathrm{mg} \mathrm{L}^{-1}$ in the gastrointestinal fluids.

$\mathrm{Fe}, \mathrm{Pb}, \mathrm{Mn}$, and Co were also solubilized into the $\mathrm{SF}_{\text {GASTRIC }}$ and $\mathrm{SF}_{\text {INTESTINAL }}$ but due to their much lower concentrations in CMTT, concentrations of only $38.4,5.1,2.5$, and $0.7 \mu \mathrm{g} \mathrm{L}^{-1}$ (corresponding to $4.6,9.0,15.8$, and $0.9 \%$ of the total metal content of CMTT, respectively) were measured after $3 \mathrm{~h}$ in $\mathrm{SF}_{\mathrm{GASTRIC}}$, and no significant desorption occurred in $\mathrm{SF}_{\text {INTESTINAL }}$.

The solubilization kinetics of $\mathrm{Zn}$ from TRWP exhibited a different pattern from that of CMTT (Figure 1). The equilibrium was rapidly reached after $30 \mathrm{~min}$ of digestion with $\mathrm{SF}_{\mathrm{GASTRIC}}$, leading to $14.5 \%$ of total $\mathrm{Zn}$ solubilized. Once again, the replacement of $\mathrm{SF}_{\text {GASTRIC }}$ by $\mathrm{SF}_{\text {INTESTINAL }}$ reinforced the solubilization of $\mathrm{Zn}$ to reach $23 \%$ of the total $\mathrm{Zn}$ solubilized into the gastrointestinal fluids at the end of the experiment.

The different solubilization kinetics between CMTT and TRWP were likely related to the size distribution of the types of particles. Indeed, as the size of TRWP was much smaller than that of CMTT (mean sizes of 45 and $188 \mu \mathrm{m}$, respectively), the specific surface area of TRWP was larger and hence probably explained the higher $\mathrm{Zn}$ solubilization rate. Additionally, it is likely that the rougher aspect and higher porosity of the TRWP than those of the smoother CMTT (Image S1) also contributes to its larger specific surface area. The impact of the particle size on the solubilization kinetics of the pollutants from other types of microplastics has recently been observed and corroborates the results obtained in our study since an increase in the solubilization rate with smaller particles was reported. ${ }^{29,30}$ As a consequence, $\mathrm{Zn}$ solubilization 


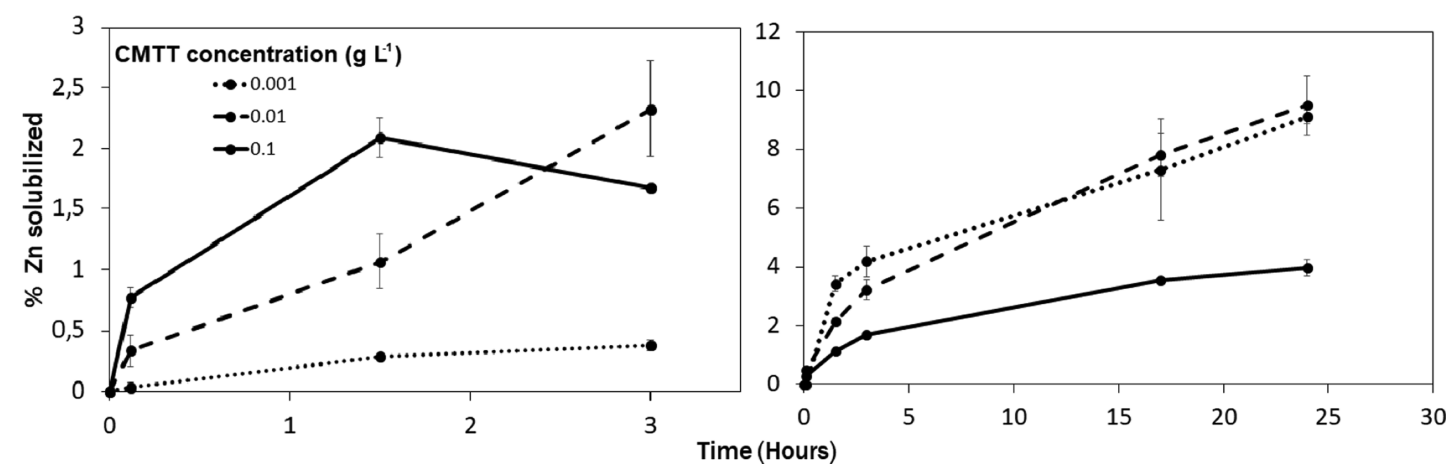

Figure 2. Percentage of $\mathrm{Zn}$ solubilized from CMTT in (a) $\mathrm{SF}_{\text {GASTRIC }}$ and (b) $\mathrm{SF}_{\text {INTESTINAL }}$ at three CMTT concentrations $(0.001,0.01$, and $0.1 \mathrm{~g}$ $\left.\mathrm{mL}^{-1}\right)$. Error bars represent the standard deviation of the replicates $(n=3)$.

from TRWP was best fitted by a pseudo-zero-order model (Table 2) before the equilibrium was reached after $30 \mathrm{~min}$ in $\mathrm{SF}_{\text {GASTRIC }}$ and by a diffusion-controlled model before the

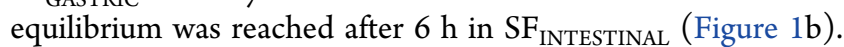
This result indicated that $\mathrm{Zn}$ was constantly solubilized without any solubility constraint and that a pseudo-equilibrium state was rapidly reached. Despite the fact that the solubilization of $\mathrm{Zn}$ from TRWP (23\%) was greater than that from CMTT (9.6\%), the concentration of $\mathrm{Zn}$ in the gastrointestinal fluids at the end of the digestion was twice as high with CMTT $\left(6709 \mu \mathrm{g} \mathrm{L}^{-1}\right)$ as that with TRWP $(3308 \mu \mathrm{g}$ $\left.\mathrm{L}^{-1}\right)$. This is due to the larger initial concentration of $\mathrm{Zn}$ in CMTT $\left(7780 \mu \mathrm{g} \mathrm{g}^{-1}\right)$ than that in TRWP $\left(1448 \mu \mathrm{g} \mathrm{g}^{-1}\right)$.

Unlike CMTT, several other metals were detected in the gastrointestinal fluids of TRWP digestion due to the contribution of the road constituent to the overall metal burden of these particles (Table 1). The solubilization kinetics of $\mathrm{Mn}, \mathrm{Co}, \mathrm{Ni}$, and $\mathrm{Ba}$ displayed a similar pattern to that for $\mathrm{Zn}$ with a rapid increase in the concentration over time to reach a steady state or a pseudo-steady state after a contact time of 26 $\mathrm{h}$ (Figure S2). The amount of metals solubilized was not proportional to their concentration in TRWP as some metals ( $\mathrm{Mn}$ and $\mathrm{Co}$ ) were more prone to solubilization than others (Ni and Ba) (Figure S3). The solubilization of other metals $(\mathrm{Cr}, \mathrm{Fe}$, and $\mathrm{Cu}$ ) present in TRWP could not be investigated because their concentration in the digesta matrix was high. Therefore, for these metals, it was not possible to distinguish the relative contribution of TRWP from the matrix background.

Overall, the solubilization of all metals was greatly enhanced (from a factor of 3.75 for Co to a factor of 12.4 for $\mathrm{Zn}$ ) both in $\mathrm{SF}_{\text {GASTRIC }}$ and $\mathrm{SF}_{\text {INTESTINAL }}$ compared to that in the MW control (Figures 1 and S3). The main differences between MW and $\mathrm{SF}_{\text {GASTRIC }}$ were $\mathrm{pH}$ (7.4 and 2.0, respectively) and the presence of Pepsin in $\mathrm{SF}_{\mathrm{GASTRIC}}$. As $\mathrm{pH}$ is a strong determinant of metal solubilization, ${ }^{28,31}$ the low $\mathrm{pH}$ of $\mathrm{SF}_{\mathrm{GASTRIC}}$ likely favored the solubilization of the metals. The negative correlation between the $\mathrm{pH}$ of aqueous solutions (including gut fluids) and solubilization of metals from polymeric matrices has been demonstrated for thermoplastics ${ }^{32,33}$ as well as tire particles. ${ }^{5,34,35}$ The SF $_{\text {INTESTINAL solution was a }}$ neutral $(\mathrm{pH}=7.4)$ complex matrix composed of high amounts of proteins, phospholipids, and bile acids. The critical micelle concentration in $\mathrm{SF}_{\text {INTESTINAL }}$ calculated from contact angle measurements was approximately equal to $2000 \mathrm{mg}_{\text {bile }} \mathrm{L}^{-1}$

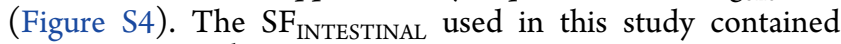
$5000 \mathrm{mg}$ bile $\mathrm{L}^{-1}$ concentration, thus well above the critical micelle concentration, indicating that $\mathrm{SF}_{\text {INTESTINAL was a }}$ micellar solution. The presence of stable micelles was confirmed by dynamic light scattering, which revealed a high concentration of micelles. Although the micelle-mediated solubilization of hydrophobic organic compounds has been demonstrated, ${ }^{36,37}$ it is possible that micelles also positively impact the solubilization of metals due to their capacity to act as a ligand. ${ }^{38}$ Furthermore, the solubilization of metals could be enhanced by complexation with natural constituents of $\mathrm{SF}_{\text {INTESTINAL }}$ such as proteins. More specifically, amino acids, such as histidine, have been identified as complexing molecules for metals. ${ }^{39-41}$

Overall, $\mathrm{Zn}$ was solubilized in much higher amounts than every other metal in the digestive fluids due to its high concentration in CMTT and TRWP (7780 and $1448 \mu \mathrm{g} \mathrm{g}^{-1}$, respectively). Although $\mathrm{Zn}$ is an essential metal and is tightly regulated, excess $\mathrm{Zn}$ can be deleterious for fish. Diet-borne $\mathrm{Zn}$ toxicity to fish has been investigated and showed contrasting results among fish species, with the effects on growth observed from $30 \mu \mathrm{g} \mathrm{Zn} \mathrm{g}_{\text {diet }}{ }^{-1}$ for guppies (Poecilia reticulata) to no observable effects on growth with up to $1500 \mu \mathrm{g} \mathrm{Zn} \mathrm{g}_{\text {diet }}{ }^{-1}$ for rainbow trout (O. mykiss). ${ }^{42,43}$ Therefore, due to (i) the high concentration of $\mathrm{Zn}$ measured in CMTT and TRWP and (ii) the high solubilization potential of $\mathrm{Zn}$ into fish simulated gastrointestinal fluids, this study aimed to further elucidate the role of tire particle ingestion for $\mathrm{Zn}$ bioaccessibility.

Influence of the CMTT Concentration on Zn Solubilization. In order to investigate the influence of the concentration of CMTT on the solubilization of $\mathrm{Zn}$, in vitro digestions with three different concentrations $(0.1,0.01$, and $0.001 \mathrm{~g} \mathrm{~mL}^{-1}$ ) were performed.

In $\mathrm{SF}_{\text {GASTRIC }}$, the solubilization kinetics were different for the three scenarios, and a positive trend between the percentage of $\mathrm{Zn}(\% \mathrm{Zn})$ solubilized and CMTT concentration was observed except for the last data point after $3 \mathrm{~h}$ (Figure $2 \mathrm{a}$ ). It is possible that the equilibrium was reached for the highest concentration tested $\left(0.1 \mathrm{~g} \mathrm{~mL}^{-1}\right)$. After $3 \mathrm{~h}, \% \mathrm{Zn}$ solubilized was $0.37-$ $2.32 \%$ for all three scenarios. In $\mathrm{SF}_{\text {INTESTINAL }}$ the solubilization kinetics were similar, and the equilibrium was not reached after $24 \mathrm{~h}$ digestion for the two lower concentrations ( 0.01 and $0.001 \mathrm{~g} \mathrm{~mL}^{-1}$ ) (Figure $2 \mathrm{~b}$ ). A slower solubilization rate was observed for the highest concentration $\left(0.1 \mathrm{~g} \mathrm{~mL}^{-1}\right)$, likely due to the near-equilibrium between CMTT and SF INTESTINAL with a high $\mathrm{Zn}$ concentration measured in the solution $(33.6 \mathrm{mg}$ $\mathrm{L}^{-1}$ at $24 \mathrm{~h}$ ), preventing faster solubilization. A decrease in the percentage of metal solubilized was also observed with the increasing CMTT concentration for various metals and was 


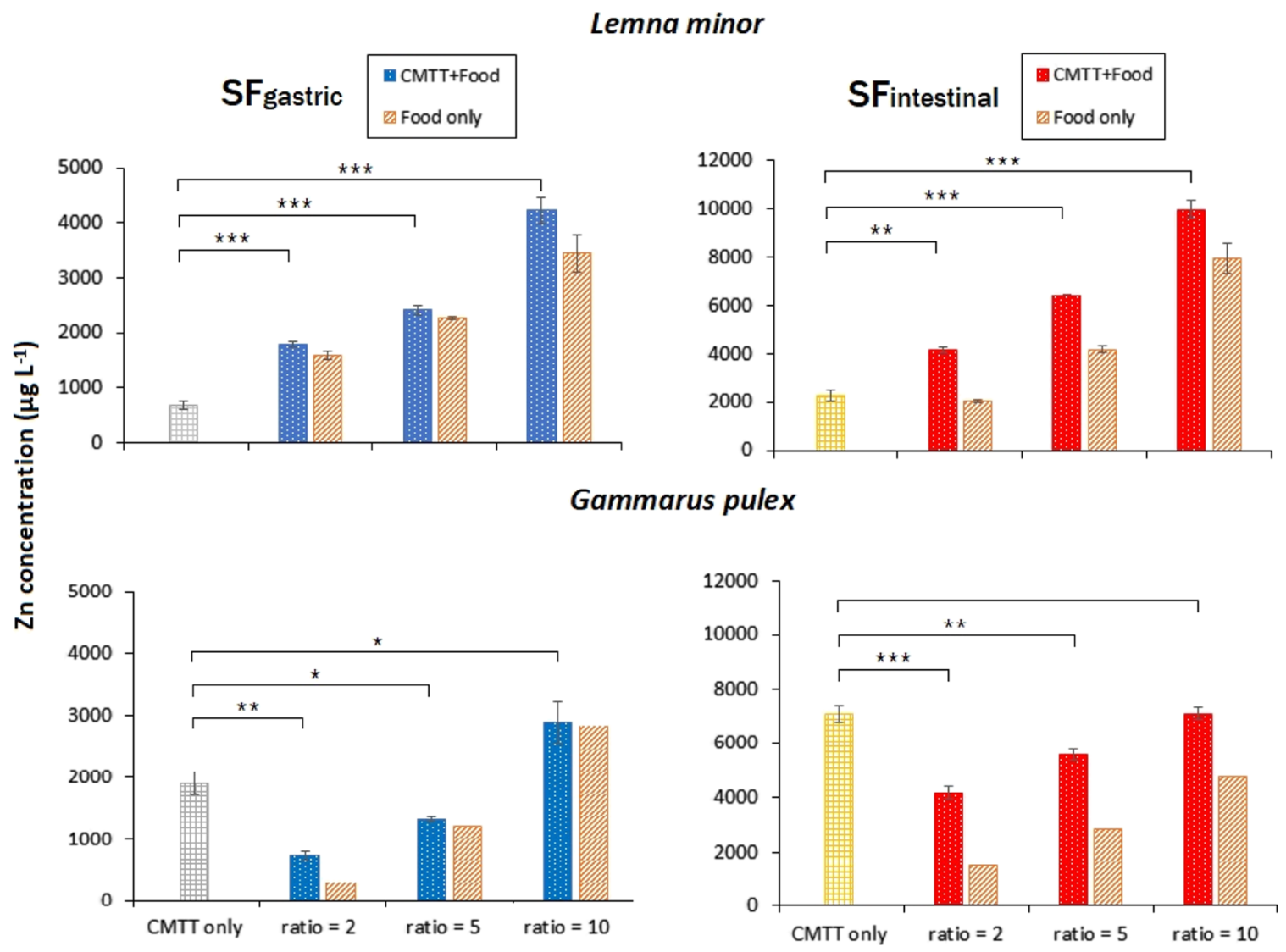

Figure 3. Concentration of $\mathrm{Zn}$ solubilized into digestive fluids under various scenarios. Concentration of $\mathrm{Zn}$ in $\mathrm{SF}_{\mathrm{GASTRIC}}(\mathrm{a}, \mathrm{b})$ and in $\mathrm{SF}_{\mathrm{INTESTINAL}}$ (c,d) after in vitro digestion simulating the coingestion of CMTT and either G. pulex or L. minor with three different food/CMTT ratios (2:1, 5:1, and 10:1). Control experiments with CMTT only are represented in gray and yellow (squared bars). Control experiments with food only are represented in orange (dashed bars). Error bars represent the standard deviation of the replicates $(n=3$ except for food only with G. pulex $n=1)$. Statistical analyses with Welch two-samples tests: $* * *$, and $* * *$ represent $p_{\text {value }}<0.05,0.01$, and 0.001 , respectively.

related to the saturation of the liquid phase. ${ }^{44}$ By adding up $\%$ $\mathrm{Zn}$ solubilized in $\mathrm{SF}_{\mathrm{GASTRIC}}$ and $\mathrm{SF}_{\text {INTESTINAL }}$ for the three scenarios, on average, $8.7 \pm 2.8 \%$ of $\mathrm{Zn}$ was solubilized in gastrointestinal fluid after a gut transit time of $27 \mathrm{~h}(3 \mathrm{~h}$ in stomach $+24 \mathrm{~h}$ in intestine). These results show that $\% \mathrm{Zn}$ solubilized in gastrointestinal fluids is mostly independent of the amount of ingested CMTT, unless saturation of the liquid phase occurs-a scenario unlikely to happen in natural environments where concentrations of TRWP in water are estimated to range from 0.5 to $5 \mathrm{mg} \mathrm{L}^{-1} \cdot{ }^{10}$ Under the assumption that these results can be extrapolated to TRWP, one can expect that $20-25 \%$ of $\mathrm{Zn}$ would be solubilized from these particles independently of the particle concentration measured in the gut (Figure 1).

Effects of Food Organic Matter Coingestion on Zn Solubilization. Two coingestion experiments of CMTT with either animal (G. pulex) or vegetal (L. minor) food organic matter were conducted. Alongside, experiments without CMTT but with food organic matter only were performed for comparison. The coingestion of L. minor resulted in a significant increase in the $\mathrm{Zn}$ concentration in both $\mathrm{SF}_{\text {GASTRIC }}$ and $\mathrm{SF}_{\text {INTESTINAL }}$ (Figure $3 \mathrm{a}, \mathrm{c}$ ). As can be deduced from Figure 3a,c, $\mathrm{Zn}$ contribution from CMTT was cumulative and added up to the $\mathrm{Zn}$ contribution from L. minor in SF INTESTINAL. The amount of $\mathrm{Zn}$ solubilized was dependent on the quantities of $L$. minor added as the concentration of soluble $\mathrm{Zn}$ increased with increasing food/CMTT ratios. Soluble $\mathrm{Zn}$ was released from $L$. minor; $31-72$ and $72-93 \%$ of its total $\mathrm{Zn}$ content were solubilized in $\mathrm{SF}_{\mathrm{GASTRIC}}$ and $\mathrm{SF}_{\text {INTESTINAL }}$, respectively (Figure S5). These results indicate that no complexation or adsorption of $\mathrm{Zn}$ solubilized from CMTT occurred on the vegetal organic matter.

In contrast, coingestion with G. pulex led to a reduction of the soluble $\mathrm{Zn}$ concentrations compared to that with the digestion of CMTT only, both in $\mathrm{SF}_{\text {GASTRIC }}$ and SF $\mathrm{SNTESTINAL}_{\text {INT }}$ at food/CMTT ratios of 2 and 5 (Figure 3b,d). For the coingestion scenario with a food/CMTT ratio of 10 , the soluble $\mathrm{Zn}$ concentration was similar to that with CMTT only. These results show that Zn solubilized from CMTT did not cumulate with $\mathrm{Zn}$ solubilized from G. pulex but was partly readsorbed or complexed by the organic matter added via $G$. pulex.

Overall, Zn solubilized from CMTT was adsorbed on, or complexed by, animal organic matter (G. pulex) but not vegetal organic matter (L. minor). One explanation for this observation could be that G. pulex is composed of $40 \%$ proteins, ${ }^{45}$ whereas L. minor has a lower protein content $(25 \%) .{ }^{46}$ Proteins and particularly metallothionein, found in animals, are strong ligands for $\mathrm{Zn}{ }^{47}$ Thus, it is possible that the complexation on metal-binding proteins was more important with the coingestion of $G$. pulex than that with L. minor. More importantly, G. pulex exoskeletons are composed of chitin, a fibrous substance consisting of polysaccharides, which has been proven to bind metal cations by the process of chelation. ${ }^{48}$ 
Therefore, it is plausible that the $\mathrm{Zn}$ cations solubilized from CMTT were subsequently bound by proteins or chitin from $G$. pulex. In a general manner, animal organic matter reduced the amount of bioavailable $\mathrm{Zn}$ solubilized from CMTT. Contrastingly, in the coingestion scenario with vegetal organic matter, high quantities of $\mathrm{Zn}$ were solubilized from L. minor for all food/CMTT ratios and cumulated with the $\mathrm{Zn}$ solubilized from CMTT.

To date, experiments investigating the coingestion of food organic matter in desorption studies of micropollutants from microplastics or tire particles remain scarce and mainly refer to organic compounds such as polychlorinated biphenyls ${ }^{37}$ or explore the particular case of deposit feeder organisms being exposed to sediment organic matter. ${ }^{39-41}$ Accounting for coingestion scenarios when performing in vitro digestion experiments of contaminated polymeric matrices is critical as it is a way to better represent the situations likely to occur in the aquatic environment. Our results demonstrated the complexity of the interactions between the different phases in the fluids, which are highly dependent on the nature of the food organic matter (vegetal vs animal). The concentrations of $\mathrm{Zn}$ in the food organic matter used for the coingestion scenarios in this study were consistent with the $\mathrm{Zn}$ contents reported in the environment for L. minor ${ }^{49}$ and G. pulex ${ }^{50,51}$ as well as with other prey types susceptible to be ingested by fish, such as various zooplankton species. ${ }^{52,53}$ However, the three food/CMTT ratios investigated were, for technical reasons (see the Material and Methods section), low and likely below the ratios encountered in the environment. Nevertheless, our results show that the addition of food organic matter could act as a strong complexant for $\mathrm{Zn}$ and might contribute to the lower bioaccessibility of this metal once released from CMTT. It was found that G. pulex and L. minor remnants could eventually be digested and act as a source of bioaccessible $\mathrm{Zn}$. For coingestion scenarios with L. minor, the $\mathrm{Zn}$ contribution from the food could significantly outweigh the $\mathrm{Zn}$ contribution from CMTT.

Environmental Implication. Our coingestion studies used CMTT as a surrogate for the more environmentally relevant TRWP. As TRWP contained lower amounts of $\mathrm{Zn}$ (Table 1) than CMTT, it is likely that the $\mathrm{Zn}$ contribution from TRWP in coingestion scenarios will be lower than what was demonstrated in this work with CMTT. Nevertheless, our study shows that tire rubber contains high amounts of $\mathrm{Zn}$ and that its solubilization within the fish digestive fluids is enhanced compared to its leaching potential in water. This pattern was also observed for other metals such as $\mathrm{Mn}, \mathrm{Co}, \mathrm{Ni}$, and $\mathrm{Ba}$. If future studies were to confirm that environmental TRWP contain these metals, the contribution of TRWP to the exposure of $\mathrm{Mn}, \mathrm{Co}, \mathrm{Ni}$, and $\mathrm{Ba}$ would need to be investigated. It is important to note that low concentrations of heavy metals could induce toxicity, potentially related to mixture effects.

In an environmentally relevant coingestion scenario of tire rubber with food organic matter, the $\mathrm{Zn}$ contribution from CMTT will represent only a fraction of the total $\mathrm{Zn}$ solubilized into the gastrointestinal fluids. Indeed, in an effort to reproduce environmentally relevant coingestion scenarios, it was shown that most of the $\mathrm{Zn}$ solubilized in the gastrointestinal fluids would be released from diet and that $20-30 \%$ of the total $\mathrm{Zn}$ solubilized would originate from CMTT. However, various organic compounds are also added as additives during the manufacture of the tire tread and are suspected to cause toxic effects to aquatic organisms. Recently,
6-PPD quinone, an oxidation product of the widely used antiozonant $N$-(1,3-dimethylbutyl)- $N^{\prime}$-phenyl-1,4-benzenediamine (6-PPD) was shown to be highly poisonous to Coho Salmon, ${ }^{54}$ highlighting the need for further studies on the bioavailability of organic additives used in the production of rubber. The methods used in this study could be applied to investigate the solubilization potential and bioaccessibility of such organic compounds in the fish gastrointestinal fluids.

\section{ASSOCIATED CONTENT}

\section{Supporting Information}

The Supporting Information is available free of charge at https://pubs.acs.org/doi/10.1021/acs.est.1c04385.

Metal analyses, physical and chemical characteristics of CMTT and TRWP, surface tension of simulated intestinal fluid ( $\mathrm{SF}_{\mathrm{INTESTINAL}}$ ), and solubilization kinetics of $\mathrm{Mn}, \mathrm{Co}, \mathrm{Ni}$, and $\mathrm{Ba}$ in $\mathrm{SF}_{\mathrm{GASTRIC}}$ and $\mathrm{SF}_{\text {INTESTINAL }}$ (PDF)

\section{AUTHOR INFORMATION}

\section{Corresponding Author}

Thibault Masset - Ecole Polytechnique Fédérale de Lausanne-EPFL, Central Environmental Laboratory, IIE, ENAC, CH-1015 Lausanne, Switzerland; 이이.org/ 0000-0001-7312-9145; Email: thibault.masset@epfl.ch

\section{Authors}

Benoit J. D. Ferrari - Ecotox Centre-EPFL ENAC IIE, GE, CH-1015 Lausanne, Switzerland; Ecotox Centre, 8600 Dübendorf, Switzerland

Dean Oldham - Department of Integrative Biology, Oklahoma State University, Stillwater, Oklahoma 74078, United States

William Dudefoi - Department Environmental Toxicology, Eawag-Swiss Federal Institute of Aquatic Science and Technology, 8600 Dübendorf, Switzerland

Matteo Minghetti - Department of Integrative Biology, Oklahoma State University, Stillwater, Oklahoma 74078, United States; @ orcid.org/0000-0003-3960-3805

Kristin Schirmer - Department Environmental Toxicology, Eawag-Swiss Federal Institute of Aquatic Science and Technology, 8600 Dübendorf, Switzerland; School of Architecture, Civil and Environmental Engineering, EPFL, Lausanne 1015, Switzerland; Institute of Biogeochemistry and Pollutant Dynamics, ETHZ, Zurich 8092, Switzerland; (1) orcid.org/0000-0003-1116-4724

Alan Bergmann - Ecotox Centre, 8600 Dübendorf, Switzerland

Etienne Vermeirssen - Ecotox Centre, 8600 Dübendorf, Switzerland

Florian Breider - Ecole Polytechnique Fédérale de Lausanne-EPFL, Central Environmental Laboratory, IIE, ENAC, CH-1015 Lausanne, Switzerland; 으이.org/ 0000-0002-5698-0314

Complete contact information is available at: https://pubs.acs.org/10.1021/acs.est.1c04385

\section{Notes}

The authors declare the following competing financial interest(s): The work presented here including the production, handling, distribution and information related to the CMTT and TRWP was funded by the World Business Council for 
Sustainable Developments (WBCSD) Tire Industry Project (TIP). TIP is a global CEO-led initiative undertaken by leading tire manufacturing companies. TIP drives research on potential human health and environmental impacts of tires throughout their lifecycle. The study design, execution, interpretation, and manuscript preparation were conducted solely by the authors.

\section{ACKNOWLEDGMENTS}

The authors would like to thank Karine Vernez and Sylvain Coudret for their assistance in sample analyses as well as Gregoire Baroz and Yann Lavanchy for their assistance during the physical characterization of the particles. The authors would also like to thank Cardno Chemrisk and particularly Marisa Kreider for the production, handling, and distribution of the CMTT and TRWP used in this study. The work presented here-including the production, handling, distribution, and information related to the CMTT and TRWP-was funded by the World Business Council for Sustainable Development's (WBCSD) Tire Industry Project (TIP). TIP is a global CEO-led initiative undertaken by leading tire manufacturing companies. TIP drives the research on potential human health and environmental impacts of tires throughout their lifecycle. The study design, execution, interpretation, and manuscript preparation were conducted solely by the authors.

\section{REFERENCES}

(1) Plastics, E. Plastics Europe. 2021 https://www.plasticseurope. org/application/files/3416/2270/7211/Plastics_the_facts-WEB2020 versionJun21_final.pdf (accessed in July 2020).

(2) Luo, Z.; Zhou, X.; Su, Y.; Wang, H.; Yu, R.; Zhou, S.; Xu, E. G.; Xing, B. Environmental Occurrence, Fate, Impact, and Potential Solution of Tire Microplastics: Similarities and Differences with Tire Wear Particles. Sci. Total Environ. 2021, 795, 148902.

(3) Boucher, J.; Faure, F.; Pompini, O.; Plummer, Z.; Wieser, O.; Felippe de Alencastro, L. (Micro) Plastic Fluxes and Stocks in Lake Geneva Basin. TrAC, Trends Anal. Chem. 2019, 112, 66-74.

(4) Kreider, M. L.; Panko, J. M.; McAtee, B. L.; Sweet, L. I.; Finley, B. L. Physical and Chemical Characterization of Tire-Related Particles: Comparison of Particles Generated Using Different Methodologies. Sci. Total Environ. 2010, 408, 652-659.

(5) Bocca, B.; Forte, G.; Petrucci, F.; Costantini, S.; Izzo, P. Metals Contained and Leached from Rubber Granulates Used in Synthetic Turf Areas. Sci. Total Environ. 2009, 407, 2183-2190.

(6) Thorpe, A.; Harrison, R. M. Sources and Properties of NonExhaust Particulate Matter from Road Traffic: A Review. Sci. Total Environ. 2008, 400, 270.

(7) Gietl, J. K.; Lawrence, R.; Thorpe, A. J.; Harrison, R. M. Identification of Brake Wear Particles and Derivation of a Quantitative Tracer for Brake Dust at a Major Road. Atmos. Environ. 2010, 44, 141-146.

(8) Hjortenkrans, D. S. T.; Bergbäck, B. G.; Häggerud, A. V. Metal Emissions from Brake Linings and Tires: Case Studies of Stockholm, Sweden 1995/1998 and 2005. Environ. Sci. Technol. 2007, 41, 52245230.

(9) Panko, J. M.; Chu, J.; Kreider, M. L.; Unice, K. M. Measurement of Airborne Concentrations of Tire and Road Wear Particles in Urban and Rural Areas of France, Japan, and the United States. Atmos. Environ. 2013, 72, 192-199.

(10) Wagner, S.; Hüffer, T.; Klöckner, P.; Wehrhahn, M.; Hofmann, T.; Reemtsma, T. Tire Wear Particles in the Aquatic Environment-a Review on Generation, Analysis, Occurrence, Fate and Effects. Water Res. 2018, 139, 83-100.

(11) Parker, B. W.; Beckingham, B. A.; Ingram, B. C.; Ballenger, J. C.; Weinstein, J. E.; Sancho, G. Microplastic and Tire Wear Particle Occurrence in Fishes from an Urban Estuary: Influence of Feeding
Characteristics on Exposure Risk. Mar. Pollut. Bull. 2020, 160, 111539 .

(12) Wieczorek, A. M.; Morrison, L.; Croot, P. L.; Allcock, A. L.; MacLoughlin, E.; Savard, O.; Brownlow, H.; Doyle, T. K. Frequency of Microplastics in Mesopelagic Fishes from the Northwest Atlantic. Front. Mar. Sci. 2018, 5, 39.

(13) Halle, L. L.; Palmqvist, A.; Kampmann, K.; Khan, F. R. Ecotoxicology of Micronized Tire Rubber: Past, Present and Future Considerations. Sci. Total Environ. 2020, 706, 135694.

(14) Baensch-Baltruschat, B.; Kocher, B.; Stock, F.; Reifferscheid, G. Tyre and Road Wear Particles (TRWP)-A Review of Generation, Properties, Emissions, Human Health Risk, Ecotoxicity, and Fate in the Environment. Sci. Total Environ. 2020, 733, 137823.

(15) Redondo-Hasselerharm, P. E.; de Ruijter, V. N.; Verschoor, A.; Koelmans, A. A. Ingestion and Chronic Effects of Car Tire Tread Particles on Freshwater Benthic Macroinvertebrates. Environ. Sci. Technol. 2018, 52, 13986-13994.

(16) Marwood, C.; McAtee, B.; Kreider, M.; Ogle, R. S.; Finley, B.; Sweet, L.; Panko, J. Acute Aquatic Toxicity of Tire and Road Wear Particles to Alga, Daphnid, and Fish. Ecotoxicology 2011, 20, 2079.

(17) LaPlaca, S. B.; van den Hurk, P. Toxicological Effects of Micronized Tire Crumb Rubber on Mummichog (Fundulus Heteroclitus) and Fathead Minnow (Pimephales Promelas). Ecotoxicology 2020, 29, 524.

(18) Martin, K.; Turner, A. Mobilization and Bioaccessibility of Cadmium in Coastal Sediment Contaminated by Microplastics. Mar. Pollut. Bull. 2019, 146, 940-944.

(19) Turner, A.; Hallett, L. Bioaccessibility of Zinc in Estuarine Sediment Contaminated by Tire Wear Particles. Water, Air, Soil Pollut. 2012, 223, 4889-4894.

(20) Kovochich, M.; Liong, M.; Parker, J. A.; Oh, S. C.; Lee, J. P.; Xi, L.; Kreider, M. L.; Unice, K. M. Chemical Mapping of Tire and Road Wear Particles for Single Particle Analysis. Sci. Total Environ. 2021, $757,144085$.

(21) ISO. Rubber-Generation and Collection of Tyre and Road Wear Particles (TRWP)—Road Simulator Laboratory Method, ISO/TS 22638, 2018.

(22) Siri, C.; Liu, Y.; Masset, T.; Dudefoi, W.; Minghetti, M.; Grandjean, D.; Breider, F. Adsorption of Progesterone onto Microplastics and Its Desorption in Simulated Gastric and Intestinal Fluids. Environ. Sci.: Processes Impacts 2021, 23, 1566.

(23) Minghetti, M.; Drieschner, C.; Bramaz, N.; Schug, H.; Schirmer, K. A Fish Intestinal Epithelial Barrier Model Established from the Rainbow Trout (Oncorhynchus Mykiss) Cell Line, RTgutGC. Cell Biol. Toxicol. 2017, 33, 539-555.

(24) Clements, K. D. Fermentation and Gastrointestinal Microorganisms in Fishes. Gastrointestinal Microbiology; Springer, 1997; pp $156-198$.

(25) Nilsson, N. H.; Malmgren-Hansen, B.; Thomsen, U. S.; Teknologisk Institut Mapping, Emissions and Environmental and Health Assessment of Chemical Substances in Artificial Turf; Danish Environmental Protection Agency Copenhagen: Denmark, 2008.

(26) Legret, M.; Odie, L.; Demare, D.; Jullien, A. Leaching of Heavy Metals and Polycyclic Aromatic Hydrocarbons from Reclaimed Asphalt Pavement. Water Res. 2005, 39, 3675-3685.

(27) Klöckner, P.; Seiwert, B.; Weyrauch, S.; Escher, B. I.; Reemtsma, T.; Wagner, S. Comprehensive Characterization of Tire and Road Wear Particles in Highway Tunnel Road Dust by Use of Size and Density Fractionation. Chemosphere 2021, 279, 130530.

(28) Ruby, M. V.; Davis, A.; Kempton, J. H.; Drexler, J. W.; Bergstrom, P. D. Lead Bioavailability-Dissolution Kinetics under Simulated Gastric Conditions. Environ. Sci. Technol. 1992, 26, 12421248.

(29) Coffin, S.; Lee, I.; Gan, J.; Schlenk, D. Simulated Digestion of Polystyrene Foam Enhances Desorption of Diethylhexyl Phthalate (DEHP) and In Vitro Estrogenic Activity in a Size-Dependent Manner. Environ. Pollut. 2019, 246, 452-462.

(30) Liu, X.; Gharasoo, M.; Shi, Y.; Sigmund, G.; Hüffer, T.; Duan, L.; Wang, Y.; Ji, R.; Hofmann, T.; Chen, W. Key Physicochemical 
Properties Dictating Gastrointestinal Bioaccessibility of MicroplasticsAssociated Organic Xenobiotics: Insights from a Deep Learning Approach. Environ. Sci. Technol. 2020, 54, 12051.

(31) Zhao, B.; Liu, A.; Wu, G.; Li, D.; Guan, Y. Characterization of Heavy Metal Desorption from Road-Deposited Sediment under Acid Rain Scenarios. J. Environ. Sci. 2017, 51, 284-293.

(32) Khan, F. R.; Boyle, D.; Chang, E.; Bury, N. R. Do Polyethylene Microplastic Beads Alter the Intestinal Uptake of Ag in Rainbow Trout (Oncorhynchus Mykiss)? Analysis of the MP Vector Effect Using in Vitro Gut Sacs. Environ. Pollut. 2017, 231, 200-206.

(33) Bakir, A.; Rowland, S. J.; Thompson, R. C. Enhanced Desorption of Persistent Organic Pollutants from Microplastics under Simulated Physiological Conditions. Environ. Pollut. 2014, $185,16-23$

(34) Gualtieri, M.; Andrioletti, M.; Vismara, C.; Milani, M.; Camatini, M. Toxicity of Tire Debris Leachates. Environ. Int. 2005, 31, 723-730.

(35) Selbes, M.; Yilmaz, O.; Khan, A. A.; Karanfil, T. Leaching of DOC, DN, and Inorganic Constituents from Scrap Tires. Chemosphere 2015, 139, 617-623.

(36) Fei, Y.-h.; Leung, K. M. Y.; Li, X.-y. Adsorption and Desorption Behaviors of Selected Endocrine Disrupting Chemicals in Simulated Gastrointestinal Fluids. Mar. Pollut. Bull. 2014, 85, 363-369.

(37) Mohamed Nor, N. H.; Koelmans, A. A. Transfer of PCBs from Microplastics under Simulated Gut Fluid Conditions Is Biphasic and Reversible. Environ. Sci. Technol. 2019, 53, 1874-1883.

(38) Pramauro, E.; Prevot, A. B. Solubilization in Micellar Systems. Analytical and Environmental Applications. Pure Appl. Chem. 1995, 67, 551-559.

(39) Chen, Z.; Mayer, L. M. Mechanisms of $\mathrm{Cu}$ Solubilization during Deposit Feeding. Environ. Sci. Technol. 1998, 32, 770-775.

(40) Lawrence, A. L.; McAloon, K. M.; Mason, R. P.; Mayer, L. M. Intestinal Solubilization of Particle-Associated Organic and Inorganic Mercury as a Measure of Bioavailability to Benthic Invertebrates. Environ. Sci. Technol. 1999, 33, 1871-1876.

(41) Mayer, L. M.; Weston, D. P.; Bock, M. J. Benzo [a] Pyrene and Zinc Solubilization by Digestive Fluids of Benthic Invertebrates-a Cross-phyletic Study. Environ. Toxicol. Chem. 2001, 20, 1890-1900.

(42) Clearwater, S. J.; Farag, A. M.; Meyer, J. S. Bioavailability and Toxicity of Dietborne Copper and Zinc to Fish. Comp. Biochem. Physiol., Part C: Toxicol. Pharmacol. 2002, 132, 269-313.

(43) Mount, D. R.; Barth, A. K.; Garrison, T. D.; Barten, K. A.; Hockett, J. R. Dietary and Waterborne Exposure of Rainbow Trout (Oncorhynchus Mykiss) to Copper, Cadmium, Lead and Zinc Using a Live Diet. Environ. Toxicol. Chem. 1994, 13, 2031-2041.

(44) Hamel, S. C.; Buckley, B.; Lioy, P. J. Bioaccessibility of Metals in Soils for Different Liquid to Solid Ratios in Synthetic Gastric Fluid. Environ. Sci. Technol. 1998, 32, 358-362.

(45) Abo-Taleb, H.; Zeina, A.; Ashour, M.; Mabrouk, M.; Sallam, A.; El-feky, M. Isolation and Cultivation of the Freshwater Amphipod Gammarus Pulex (Linnaeus, 1758), with an Evaluation of Its Chemical and Nutritional Content. Egypt. J. Aquat. Biol. Fish. 2020, 24, 69-82.

(46) Appenroth, K.-J.; Sree, K. S.; Böhm, V.; Hammann, S.; Vetter, W.; Leiterer, M.; Jahreis, G. Nutritional Value of Duckweeds (Lemnaceae) as Human Food. Food Chem. 2017, 217, 266-273.

(47) Krężel, A.; Maret, W. The Biological Inorganic Chemistry of Zinc Ions. Arch. Biochem. Biophys. 2016, 611, 3-19.

(48) Camci-Unal, G.; Pohl, N. L. B. Quantitative Determination of Heavy Metal Contaminant Complexation by the Carbohydrate Polymer Chitin. J. Chem. Eng. Data 2010, 55, 1117-1121.

(49) Drost, W.; Matzke, M.; Backhaus, T. Heavy Metal Toxicity to Lemna Minor: Studies on the Time Dependence of Growth Inhibition and the Recovery after Exposure. Chemosphere 2007, 67, $36-43$.

(50) Xu, Q.; Pascoe, D. The Bioconcentration of Zinc by Gammarus Pulex (L.) and the Application of a Kinetic Model to Determine Bioconcentration Factors. Water Res. 1993, 27, 1683-1688.
(51) Xu, Q.; Pascoe, D. The Importance of Food and Water as Sources of Zinc during Exposure of Gammarus Pulex (Amphipoda). Arch. Environ. Contam. Toxicol. 1994, 26, 459-465.

(52) Hamanaka, T.; Tsujita, T. Cadmium and Zinc Concentrations in Zooplankton in the Subarctic Region of the North Pacific. J. Oceanogr. Soc. Jpn. 1981, 37, 160-172.

(53) Fisher, N.; Stupakoff, I.; Sañudo-Wilhelmy, S.; Wang, W.; Teyssié, J.; Fowler, S.; Crusius, J. Trace Metals in Marine Copepods: A Field Test of a Bioaccumulation Model Coupled to Laboratory Uptake Kinetics Data. Mar. Ecol.: Prog. Ser. 2000, 194, 211-218.

(54) Tian, Z.; Zhao, H.; Peter, K. T.; Gonzalez, M.; Wetzel, J.; Wu, C.; Hu, X.; Prat, J.; Mudrock, E.; Hettinger, R.; Cortina, A. E.; Biswas, R. G.; Kock, F. V. C.; Soong, R.; Jenne, A.; Du, B.; Hou, F.; He, H.; Lundeen, R.; Gilbreath, A.; Sutton, R.; Scholz, N. L.; Davis, J. W.; Dodd, M. C.; Simpson, A.; McIntyre, J. K.; Kolodziej, E. P. A Ubiquitous Tire Rubber-Derived Chemical Induces Acute Mortality in Coho Salmon. Science 2021, 371, 185. 